\author{
Universidade de São Paulo \\ Escola Superior de Agricultura "Luiz de Queiroz" \\ Centro de Energia Nuclear na Agricultura
}

Genética, genômica e o fenômeno ecológico evolutivo humano

Débora Alexandra Casagrande Santos

Tese apresentada para obtenção do título de
Doutora em Ciências. Área de concentração:
Ecologia Aplicada

Piracicaba

2017 
Dados Internacionais de Catalogação na Publicação DIVISÃO DE BIBLIOTECA - DIBD/ESALQ/USP

Santos, Débora Alexandra Casagrande

Genética, genômica e o fenômeno ecológico evolutivo humano/ Débora Alexandra Casagrande Santos. - - versão revisada de acordo com a resolução CoPGr 6018 de 2011. - - Piracicaba, 2017. $100 \mathrm{p}$

Tese (Doutorado) - - USP / Escola Superior de Agricultura "Luiz de Queiroz". Centro de Energia Nuclear na Agricultura.

1. Ecologia 2. Evolução 3. Tecnologia 4. Ética 5. Cultura I. Título 


\section{Genética, genômica e o fenômeno ecológico evolutivo humano}

Ao se estudar o fenômeno ecológico evolutivo humano, estabelece-se um universo relacional, de múltiplas interfaces, no qual a condição humana não pode ser reduzida nem à cultura nem ao determinismo genético. Questiona-se se subjacente às tecnologias geradas através das pesquisas em Genética e Genômica humanas, em particular nas que se apoiam nos dados e conclusões gerados pelo HGP (The Human Genome Project) e ENCODE (Encyclopedia of DNA Elements), são consideradas eventuais interações que possam refletir-se no fenômeno ecológico evolutivo humano. Pondera-se que o ritmo com que tais tecnologias vêm sendo incorporadas às nossas vidas, não tem permitido abordar suas implicações para o fenômeno em questão. Isso, eventualmente, pode colocar em risco a sustentabilidade da vida e a condição de humanidade. Para o desenvolvimento da pesquisa adotou-se uma orientação metodológica qualitativa, buscando os dados através de literatura e em portais abertos na internet. Analisou-se e interpretou-se, de acordo com referenciais teóricos da Ecologia Evolutiva Humana e do conceito de adaptação, como as novas tecnologias associadas à Genética e à Genômica humanas, podem influenciar o fenômeno ecológico evolutivo humano. O presente trabalho também permitiu desenvolver uma reflexão ética, frente a essas tecnologias. 


\section{ABSTRACT \\ Genetics, genomics and human ecological and evolutionary phenomenon}

When studying the human evolutionary ecological phenomenon, a relational universe of multiple interfaces is established in which the human condition can not be reduced either to culture or to genetic determinism. It is questioned whether the technologies generated by research in human Genetics and Genomics, in particular those based on the data and conclusions generated by the HGP (The Human Genome Project) and ENCODE (Encyclopedia of DNA Elements), are considered as possible interactions, that can be reflected in the human evolutionary ecological phenomenon. It is thought that the pace with which such technologies are being incorporated into our lives has not allowed us to address their implications for the phenomenon in question. This may eventually jeopardize the sustainability of life and the condition of humanity. For the development of the research a qualitative methodological orientation was adopted, searching the data through literature and in open portals in the internet. It was analyzed and interpreted, according to theoretical references of Human Evolutionary Ecology and the concept of adaptation, as the new technologies associated with human Genetics and Genomics, can influence the human evolutionary ecological phenomenon. The present work also allowed to develop an ethical reflection, facing these technologies.

Keywords: Ecology; Evolution; Technology; Ethics; Culture 


\section{INTRODUÇÃO}

"Numa viagem a um país do Oriente, o senhor Palomar comprou um par de pantufas num bazar. De volta a casa, tenta calçá-las: dá-se conta de que uma delas é maior que a outra e lhe escorrega do pé (...) 'Talvez agora', pensa o senhor Palomar, 'um outro homem esteja caminhando em algum país com duas pantufas desparelhadas' (...) 'Talvez também ele neste momento pense em mim, espere encontrar-me para fazer a troca. O vínculo que nos une é mais concreto e claro do que a maior parte das relações que se estabecem entre os seres humanos. Contudo jamais nos encontraremos'”. (...)

Italo Calvino. A pantufa desparelhada. Palomar,

1994.

Visando ampliar a compreensão sobre as interações entre o fenômeno ecológico evolutivo humano e o uso de tecnologias associadas à Genética e Genômica na sociedade contemporânea, observou-se que o objeto de análise, por ser complexo, não tem limites definidos em uma área específica do conhecimento, demandando abordagem interdisciplinar e estudos em Ecologia, Antropologia e Filosofia. Áreas essas, que podem se complementar, ora se tangenciar e, até mesmo, se excluirem reciprocamente.

Assim, um dos desafios deste trabalho, desde o início, foi resgatar um referencial teórico que pudesse ser consistente, mas flexível o bastante, de forma a permitir o diálogo entre tais disciplinas e estudar o fenômeno ecológico evolutivo humano, cientes de que:

\footnotetext{
(...) qualquer mudança política ou social profunda refletir-se-á no conjunto de genes da população sujeita a essa mudança. Isso é uma consequência do fato de que a intensidade bem como a direção das forças seletivas naturais depende do ambiente, e o ambiente que exerce uma influência decisiva na espécie humana é o ambiente social (DOBZHANSKY, 1968, p. 358).
}

As leituras realizadas permitiram concluir que um quadro teórico interdisciplinar, visando estudar a evolução humana através de uma perspectiva ecológica, sem incorrer em reducionismos ou determinismos deveria se orientar por abordagens relacionais, em vários níveis de organização (dos genes à cultura). Além disso, deveria oferecer argumentos que permitissem ir além das visões da Ciência e que procurassem na Filosofia suas raízes.

Dadas as considerações, reforçou-se a compreensão da importância do resgate epistemológico no trabalho científico. Através de Moraes (1994) observou-se que "é a epistemologia que permite agregar os novos conhecimentos que o desenvolvimento da pesquisa vai trazendo. Isto é, quem faz o balanço crítico das novas técnicas, dos novos 
paradigmas, das novas teorias, é o acompanhamento epistemológico" (MORAES, 1994, p. 46). Ainda de acordo com o autor, se concluiu que o exposto pode ser aplicado a qualquer domínio da ciência, especialmente quando se trata de uma área que não se encaixa facilmente nos paradigmas tradicionais. Assim, se diante da indagação "de que ser estamos falando?" a resposta não ocorre de pronto, chega-se a um "universo interdisciplinar difuso, cuja delimitação ontológica não está feita" (MORAES, 1994, p. 46).

A importância da linguagem foi ressaltada por Moraes (1994), situando-a como um patamar elementar para que se estabeleça uma relação comunicativa entre diferentes áreas, ciências e pesquisas, justificando que “"concreto’ para um filósofo, é um nível de apreensão do real; para um engenheiro, trata-se de uma massa para edificações (...) Os exemplos poderiam ser multiplicados, mostrando que a questão da linguagem não é secundária" (MORAES, 1994, p. 51).

Também desafiador foi encontrar uma orientação metodológica que contemplasse o caminho do processo científico. Naquele momento, refletindo sobre Martins (2004) considerou-se que a metodologia de pesquisa científica depende, em grande parte, do tipo de problema a ser investigado e dos objetivos da pesquisa. A partir do delineamento dos objetivos, o que se buscou foi um caminho que pudesse ser inquisitivo, exploratório e também interpretativo.

Dessa forma, na Seção 2, a título de Materiais e Métodos, foram apresentados: o problema a ser investigado; a hipótese para estudo; os objetivos da pesquisa e a orientação metodológica adotada. Na mesma Seção, foram organizados quadros teóricos, a partir de literatura, que permitiram um alargamento sobre os conceitos de evolução, genes e cultura. Em paralelo destacaram-se referenciais da filosofia da tecnologia e ética, trazendo elementos que possibilitaram abrir um diálogo entre essas diferentes áreas.

$\mathrm{Na}$ Seção 3, como Resultados, foram apresentadas informações associadas à Genética e Genômica, disponíveis nos sites de instituições públicas financiadoras de pesquisas científicas e obtidas em literatura. A base SciELO (Scientific Eletronic Library Online) também foi adotada e as buscas realizadas através das palavras chaves: genética e ética. Os resultados foram oganizados e explicitados em quadro descritivo e posteriormente debatidos à luz do referencial teórico.

Através da Discussão, na Seção 4, foi possível interpretar os resultados sob a perspectiva ética, visando uma nova compreensão sobre o fenômeno estudado.

E finalmente, na Seção 5, à título de Conclusão abriu-se aos diálogos possíveis. 


\section{CONCLUSÃO}

O presente trabalho permitiu articular dados e conceitos, de forma a direcionar outros olhares aos estudos sobre o fenômeno ecológico evolutivo humano inerentemente associado à Genética e à Genômica, possibilitando novas perspectivas e interpretações. Evidenciou-se a complexidade da questão ética intrinsecamente envolvida, resgatando a vida como valor, frente ao relevante papel que a cultura tecnológica assume na sociedade contemporânea. Foi possível reforçar a importância do desenvolvimento de pesquisas interdisciplinares, pois embora existam diferentes ciências e metodologias associadas para se estudar as relações do ser humano com o meio, com outras formas de vida e consigo próprio, a diversidade não se reduz a elas, pois são apenas modelos incompletos e claudicantes. Para a compreensão de fenômenos complexos (como o ecológico evolutivo humano) em uma sociedade tecnológica, o diálogo é fundamental. Mais que críticas mútuas caberia à Antropologia e à Ecologia Evolutiva Humana a busca de encontros interdisciplinares, através de uma ampla discussão sobre o conceito de adaptação. Conceito inexplorado nos artigos examinados - embora alguns deles tenham discorrido sobre risco genético e eugenia refletindo assim um distanciamento na compreensão dos autores sobre as interações entre genes e cultura.

Durante a pesquisa adquiriu-se consciência, além de conhecimentos, e a real compreensão de que a adaptabilidade de nossa espécie encontra-se além dos genes e se sustenta na manutenção da diversidade, tanto biológica como cultural. Os resultados encontrados e descritos, no entanto, não corroboram essa compreensão, pois através dos artigos, evidenciou-se que o desenvolvimento tecnológico, como valor em si, está muito presente no meio acadêmico, deslocando o valor supremo da vida em si para a vida firmada na tecnocracia. Dita-se um ritmo de apropriação e incorporação das novas tecnologias, tomando-as como um paradigma, muitas vezes de forma irrefletida e guiada por valores de mercado. Situações descritas, como discriminação genética de atletas e trabalhadores possuidores de traço falciforme, organização de banco de dados genéticos visando aptidão esportiva, apenas evidenciam que a ecologia evolutiva humana, como fenômeno complexo, não vem sendo considerada. Essa postura, no entanto, diferenciou-se em alguns artigos que consideraram interações ambientais sem, no entanto, trazer à discussão conceitos ecológicos.

Como seres humanos, Homo sapiens e habitantes do planeta Terra, não é possível desconsiderar nossa “condição natural”. Mutações genéticas e epigenéticas, seleção natural, deriva genética e migrações nos constituíram e continuam a nos constituir em estreita relação 
com a cultura. Nosso futuro continua incerto, a despeito de estarmos ancorados em tecnologias e tecnocracias que nos fazem vislumbrar o prolongamento da vida e o controle de angústias e sofrimentos. Tanto a elaboração de códigos de ética visando normatizar a utilização das tecnologias associadas à Genética e à Genômica, embora importantes, como os detalhados estudos moleculares de interação genes-proteínas, vêm ocorrendo apenas há um curto intervalo de tempo em nossa breve história evolutiva.

Assim, através dos resultados encontrados não se rejeita a hipótese inicialmente levantada, podendo-se assumir que as orientações e manifestações do meio acadêmico e pesquisadores, em face do fenômeno ecológico-evolutivo humano, em geral não tem adotado uma abordagem interdisciplinar e ética, como ciência do agir refletido, quanto à sua própria influência nesse processo. 


\section{REFERÊNCIAS}

ABRANOVAY, R. A heurística do medo, muito além da precaução. Estudos Avançados, 30 (86), 2016.

ACOT, P. História da Ecologia. 2. Ed. Rio de Janeiro: Campus, 1990.

ADAMS, C. Estratégias adaptativas de duas populações caboclas (Pará) aos ecossistemas de várzea estuarina e estacional: uma análise comparativa. Tese de doutorado, IB, USP. São Paulo, 2002.

ADORNO, T. W. e HORKHEIMER, M. Dialética do Esclarecimento: fragmentos filosóficos. Rio de Janeiro: Zahar, 1985.

ANDRADE, C. D. Corpo. Novos Poemas. Rio de Janeiro: Record, 1987.

APPOLINÁRIO, F. Metodologia da ciência. Filosofia e prática da pesquisa (2 $2^{\underline{a}}$ edição). São Paulo: CENGAGE Learning, 2012.

BAIARDI, D. C. Conhecimento, evolução e complexidade na filosofia sintética de Herbert Spencer. 2008. Dissertação (Mestrado em Filosofia) - Faculdade de Filosofia, Letras e Ciências Humanas, Universidade de São Paulo, São Paulo, 2008. Disponível em: <http://www.teses.usp.br/teses/disponiveis/8/8133/tde-10022009-125210/>. Acesso em: dezembro, 2013.

BALÉE, W. e ERICKSON, C. L. Time and Complexity in Historical Ecology. New York: Columbia University Press, 2006.

BATTESTIN, C. e GHIGGI, G. O Princípio Responsabilidade de Hans Jonas: um princípio ético para os novos tempos. Thaumazein, Santa Maria, Ano III, n. 06, p. 69-85, out. 2010. Disponível em: <http://sites.unifra.br/thaumazein>. Acesso em: 26 jun. 2013.

BAUMAN, Z. Ensaios sobre o conceito de cultura. Rio de Janeiro: Zahar, 2012.

BEGOSSI, A. Ecologia Humana: Um enfoque das relações Homem-Ambiente. Interciencia 18 (1): 121-132. 1993. Disponível em: <http://www.interciencia.org.ve>. Acesso em: 25 mai. 2017.

Begossi, A. (org.) Ecologia de Pescadores da Mata Atlântica e da Amazônia. São Paulo: Hussitec: Nepan/ Unicamp: Napaub: USP: Fapesp, 2004. 332 p.

BORGMANN, A. Technology as a Cultural Force for Alena and Griffin. The Canadian Journal of Sociology / Cahiers canadiens de sociologie. Vol. 31, No. 3 (Summer, 2006), pp. 351-360. Disponível em:

$<$ http://www.jstor.org/stable/20058714?seq=1\#page_scan_tab_contents>. Acesso em: 12 abr. 2017. 
BOYD, R. Culture and the Evolutionary Process. Paperback edition. Chicago: The University of Chicago Press, 1988. Disponível em:

$<$ http://books.google.com.br/books?id=MBg4oBsCKU8C\&printsec=frontcover\&dq= editions:6T2RrXRqUUMC\&hl=pt-

BR\&sa $=X \& e i=D d V j V P e h D 4 W X N u z Q g M g E \&$ redir_esc $=y \#_{v}=$ onepage\&q\&f $=$ false $>$ . Acesso em: 12 nov. 2014.

BRANDÃO, L. R. et al. Alcaptonúria (ocronose): relato de dois casos. Rev. Bras.

Reumatol. São Paulo, v. 46 n. 5, set./out. 2006. Disponível em: <www.scielo.br/scielo.php?pid=S0482-0042006000500014\&script=sci_arttext $>$.

Acesso em: 28 ago. 2012.

CALVINO, I. Palomar. São Paulo: Cia das Letras, 1994.

CASTORIADIS, C. As encruzilhadas do labirinto II. Os Domínios do Homem. Tradução Marques, J. O. de A. Rio de Janeiro: Paz e Terra, 1987.

CASTRO, C. (org.) Evolucionismo Cultural: Textos de Morgan, Tylor e Frazer. $2^{\mathrm{a}}$ Edição. Rio de Janeiro: Jorge Zahar, 2009. Disponível em:

$<$ http:/ / books.google.com.br/books?id=cycPyWZktwQC\&printsec $=$ frontcover\&dq $=e$ volucionismo + cultural\&hl $=\mathrm{pt}-$

BR\&sa $=$ X\&ei $={ }_{n} K A I V N v n H J C v g g T Z q 4 D A B A \& r e d i r \_e s c=y \#_{v}=$ onepage\&q $=$ evoluci onismo \%20cultural\&f=false $>$. Acesso em: out. 2014.

CAVALLI-SFORZA, L., CAVALLI-SFORZA, F. Quem somos? História da Diversidade Humana. São Paulo: Editora UNESP, 2002.

COLTRO, A. A Fenomenologia: Um enfoque metodológico para além da modernidade. Caderno de Pesquisas em Administração. São Paulo, v.1, n. 11. 1o trimestre de 2000. P. 37-45. Disponível em: <http://www.regeusp.com.br/arquivos/C11-art05.pdf> Acesso em: 20 abr. 2017.

CUPANI, A. A tecnologia como problema filosófico: três enfoques. Scientia e Studia, São Paulo, v.2, n.4, p. 493-518, 2004.

DALLARI, S. G., CASTELLARO, F. A. B., GUERRIERO, I. C. Z. Biobanking and privacy law in Brazil. The Journal of Law, Medicine \& Ethics. Volume 43, Issue 4, Winter 2015, Pages: 714-725. Version of Record on line: 29 DEC 2015, DOI: $10.1111 / j$ lme.12314

DARWIN, C. Origem das Espécies. São Paulo: Editora da USP, 1985 (original de 1859). 


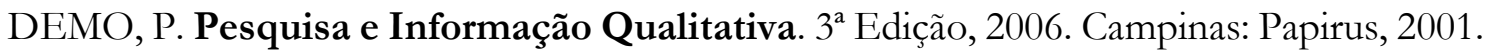
Disponível em: <http://books.google.com.br/books?id=BpPGYV28_X0C\&printsec=frontcover\&hl= pt-BR\&source $=$ gbs_vpt_buy\#v $=$ onepage\&q\&f=false $>$. Acesso em: 30 ago. 2013.

DOBZHANSKY, T. O Homem em evolução. São Paulo: Polígono, 1968.

DURHAN, W. H. Annu. Rev. Anthropol. 1990; 19:187-210. Disponível em: < http://www.annualreviews.org/toc/anthro/19/1>. Acesso em: 17 out. 2017.

EDELSTEIN, M. L.; ABEDI, M. R.; WIXON, J. Gene Therapy Clinical Trials Worldwide to 2007 - an update. The Journal of Gene Medicine. 2007; 9: 833- 842. Disponível em: <http://onlinelibrary.wiley.com/doi/10.1002/jgm.1100/pdf>. Acesso em: 13 nov. 2014.

ELLEN, R. R. Adaptation: a summary and reconsideration. In: Environment, Subsistence and System: the ecology of small-scale social formations. Cambridge: Cambridge University Press, 1982.

EHRLICH, P. R. Human natures - genes, culture and the human prospect. United States of America: Penguin Books, 2002.

FAZENDA, I. C. A.; TAVARES, D. E.; GODOY, H. P. Interdisciplinaridade na pesquisa científica. Campinas, SP: Papirus, 2015.

FEENBERG, A. O que é filosofia da tecnologia. In: A teoria crítica de Andrew Feenberg: racionalização democrática poder e tecnologia. Brasilia: UnB, 2013.

FELDMAN, M.; CAVALLI-SFORZA, L.L. Cultural and biological evolutionary processes, selection for a trait under complex transmission. Theoretical Population Biology. Vol. 9, Issue 2, pages 238-259, (April 1976). Disponível em: $<$ http://www.sciencedirect.com/science/journal/00405809/9/2>. Acesso em:12 nov. 2014.

FONSECA, L. S. G. Hans Jonas e a responsabilidade do homem frente ao desafio biotecnológico. Tese de Doutorado. UFMG, 2009. Disponível em: <www.bibliotecadigital.ufmg.br > ... > Teses de Doutorado>. Acesso em: 30 ago. 2013.

GEERTZ, C. A Interpretação das Culturas. 1ª Edição. 13ª Reimpressão. Rio de Janeiro: LTC, 2008.

GEERTZ, C. A transição para a humanidade. Panorama da Antropologia, Sol Tax (editor). Rio de Janeiro, Fundo de Cultura, p. 31-38, 1966. 
GINN, L. S. et al. Gene therapy clinical trials worldwide to 2012 - an update. Review Article. In: In: The Journal of Gene Medicine, J Gene Med 2013; 15:65-77. Published online in Wiley Online Library (wileyonlinelibrary.com) DOI: 10.1002/jgm.2698.

GRAY, D. E. Pesquisa no Mundo Real. 2a Edição. Porto Alegre, Artmed/ Penso, 2012. Disponível em: https://books.google.com.br/books?id=uQSpDAAAQBAJ\&printsec=frontcover\&hl $=$ pt-BR\&source $=$ gbs_ge_summary_r\&cad $=0 \#_{\mathrm{v}}=$ onepage\&q\&f$=$ false $>$. Acesso em: 11 maio 2017.

HARRISON, G. A. (ed.) Human adaptation. Biosocial societies series. Oxford, Oxford University, 1993.

HAWKS, J. et al. Recent acceleration of human adaptive evolution. PNAS - Proceedings of the National Academy of Sciences of the United States of America, v.104, n. 52, p. 20753-20758, December 26, 2007. Disponível em: <http://www.pnas.org/content/104/52/20753.full.pdf+html>. Acesso em: 30 ago. 2013.

HENN, B. M. et al. Hunter-gatherer genomic diversity suggests a southern African origin for modern humans. PNAS - Proceedings of the National Academy of Sciences of the United States of America, v. 108, n. 13, p. 5154-5162, March 29, 2011. Disponível em: <www.pnas.org/content/108/13/5154.full>. Acesso em: 28 ago. 2012.

INGOLD, T. Consideraciones de un antropólogo sobre la biologia. Cultura y Natureza. Aproximaciones a propósito del bicentenario de la independencia de Colombia (2011). Editor: Leonardo Montenegro Martínez.

INGOLD, T. The perception of the environment. Essays on livelihood, dwelling and skill. London and New York: Routledge, 2000. Tradução: Ciméa Barbato Bevilaqua. In: Ponto Urbe traduções: 'Gente como a gente' O conceito de homem anatomicamente moderno. Disponível em: <http://www.pontourbe.net/edicao9-traducoes/213-gente-como-agente-o-conceito-de-homem-anatomicamente-moderno >. Acesso em: dezembro/ 2013.

JABLONKA, E. e LAMB, M. Evolução em quatro dimensões. DNA, Comportamento e a História da Vida. São Paulo: Companhia das Letras, 2010.

JOAQUIM, L. M. e EL-HANI, C. N. A genética em transformação: crise e revisão do conceito de gene. Scientia e studia, São Paulo, v. 8, n. 1, p. 93-128, 2010.

JONAS, H. Ética, medicina e técnica. Lisboa: Vega, 1994.

JONAS, H. O princípio responsabilidade: Ensaio de uma ética para a civilização tecnológica. Rio de Janeiro: Contraponto/ Ed. PUC-Rio, 2006. 
LEITE, M. N. Biologia total: Hegemonia e informação no genoma humano. 2005. Tese de Doutorado. IFCH, UNICAMP, Campinas, 2005. Disponível em: $<$ http://cutter.unicamp.br/document $/$ ?code $=$ vtls000366927 $>$. Acesso em: 30 ago. 2013.

LEWENS, T. Cultural Evolution. The Stanford Encyclopedia of Philosophy. Spring 2013 Edition, Edward N. Zalta (ed.), URL = $<$ http://plato.stanford.edu/archives/spr2013/entries/evolution-cultural/>. Acesso em: dezembro/ 2013.

LIU, Y. A new perspective on Darwin's Pangenesis. In: Biol Rev Camb Philos Soc. 2008 May; 83(2):141-9. Disponível em: <https://www.ncbi.nlm.nih.gov/pubmed/18429766>. Acesso em: 25 mai. 2017.

LINDEN, R. Terapia gênica: o que é, o que não é e o que será. Estudos Avançados. vol. 24, n. 70. São Paulo, 2010. Disponível em: <http://www.scielo.br/scielo.php?pid=S010340142010000300004\&script=sci_arttext>. Acesso em: 23 ago. 2014.

LUMSDEN, C. J.; WILSON, E. O. Genes, Mind and Culture the coevolutionary process. 25 th anniversary edition. Singapore: World Scientific Printers, 2005.

MARTINS, H. H. T. de S. Metodologia qualitativa de pesquisa. Educação e Pesquisa, Universidade de São Paulo, São Paulo, v. 30, n. 2, p. 289-300, maio/ ago. 2004.

MAX PLANCK INSTITUTE FOR EVOLUTIONARY ANTHROPOLOGY. Disponível em: <http://www.eva.mpg.de/neandertal/index.html>. Acesso em: 28 ago. 2012.

MAYR, E. What evolution is. New York: Basic Books, 2001.

MAYR, E. Biologia, Ciência Única. São Paulo: Companhia das Letras, 2005.

MAYR, E. Uma ampla discussão. Charles Darwin e a Gênese do Moderno Pensamento Evolucionário. Ribeirão Preto: FUNPEC, 2006.

MINAYO, M. C. de S. (organizadora) Pesquisa Social. Teoria, método e criatividade. Petrópolis: Vozes, 2009.

MIR, L. (organizador) Genômica. São Paulo: Atheneu, 2004.

MORAES, A. C. R. Meio Ambiente e Ciências Humanas. São Paulo, Hucitec, 1994. 100 p.

MORAN, E. F. Adaptabilidade humana. São Paulo: Edusp, 1994.

NARDI, N. B. Doenças Genéticas. Gênicas, cromossômicas, complexas. In: Genômica. São Paulo: Atheneu, 2004. 
NATURE INTERNACIONAL WEEKLY JOURNAL OF SCIENCE. The chimpanzee genome.

Disponível

em:

<http://www.nature.com/nature/focus/chimpgenome/index.html>. Acesso em: 28 ago. 2012.

NCBI. National Center for Biotecnology Information - Human Genome Resources. Disponível em: <http://www.ncbi.nlm.nhi.gov/projects/genome/guide/ human/index.shtml>. Acesso em: 28 ago 2012.

NEDER, R. T. (organizador) A teoria crítica de Andrew Feenberg: racionalização democrática poder e tecnologia. Brasilia: UnB, 2013.

NEVES, W. Antropologia Ecológica. São Paulo: Cortez, 2002.

ORLOVE, B. S. Ecological anthropology. Annu. Rev. Anthropol. 9: 235-237.

POSTMAN, N. Tecnopólio. A Rendição da cultura à tecnologia. São Paulo: Nobel, 1994.

RAPCHAN, E. S. Chimpanzés possuem cultura? Questões para a antropologia sobre um tema "bom para pensar". Revista de Antropologia, São Paulo, USP, v. 48, n. 1, p. $227-$ 280, 2005. Disponível em: <http://www.scielo.br/pdf/ra/v48n1/a06v48n1.pdf>. Acesso em: 28 ago. 2012.

RAPCHAN, E. S. e NEVES, W. A. Chimpanzés não amam! Em defesa do significado. Revista de Antropologia, São Paulo, USP, v. 48, n. 2, p. 649-698, 2005. Disponível em: $<$ www.scielo.br/scielo.php?pid=S0034-77012005000200008\&script=sci_arttext $>$.

Acesso em: 28 ago. 2012.

RIDLEY, M. O que nos faz humanos. Genes, natureza e experiência. Rio de Janeiro: Record, 2004.

SÁ, S. Interdisciplinaridade: sim e não a vasos comunicantes em educação pós-graduada. Cadernos de Saúde Pública, Rio de Janeiro, 3 (3), p. 272-279, jul./set. 1987. Disponível em: $\quad<$ http://www.scielo.br/scielo.php?script=sci_arttext\&pid=S0102311X1987000300006>. Acesso em: 30 ago. 2013.

SAHLINS, M. O "Pessimismo sentimental" e a experiência etnográfica: por que a cultura não é um “objeto” em via de extinção (Parte I). MANA 3(1):41-73, 1997.

SAK, J. et al. Population biobanking in selected European countries and proposed model for a Polish national DNA bank. In: Journal of applied genetics, May; 53(2): 159-165 2012.

SALZANO, F. M. Genômica - para onde caminha a humanidade? In: Genômica. São Paulo: Atheneu, 2004. 
SANTOS, D. A. C. Educação Ambiental: Práticas e Concepções em Quatro Organizações Governamentais no Estado de São Paulo. Dissertação de Mestrado. FE, UNICAMP, Campinas, 2001.

SCHUTKOWSKI, H. Human Ecology Biocultural Adaptions in Human Communities. Ecological Studies, vol. 182. Springer: Germany. 2006. 306 p.

SOKOLOWSKI, R. Introdução à Fenomenologia. São Paulo: Edições Loyola, 2004. Disponível em: $<$ https://books.google.com.br/books?id=4J6zEGEf7LgC\&pg=PA3\&lpg=PP1\&f ocus $=$ viewport\&hl $=\mathrm{pt}-\mathrm{BR} \# \mathrm{v}=$ onepage $\& \mathrm{q} \& \mathrm{f}=$ false $>$ Acesso em: 11 maio 2017.

STANFORD ENCYCLOPEDIA OF PHILOSOPHY. Disponível em: <http://plato.stanford.edu/entries/human-genome/>. Acesso em: 26 ago. 2012.

STOCK, J. T. Are humans still evolving? Technological advances and unique biological characteristics allow us to adapt to environmental stress. Has this stopped genetic evolution? Science \& Society, EMBO reports. 9, S51 - S54, 2008. Disponível em: < http://www.nature.com/embor/journal/v9/n1s/full/embor200863.html >. Acesso em: 30 ago. 2013.

THE JOURNAL OF GENE MEDICINE. Disponível em: <http://www.abedia.com/wiley/>. Acesso em 13 nov. 2014.

THIOLLENT, M. J-M. Aspectos Qualitativos da Metodologia de Pesquisa com objetivos de descrição, avaliação e reconstrução. Cad. Pesq. (49): 45-50, maio 1984. Disponível em: <http://educa.fcc.org.br/pdf/cp/n49a05.pdf>. Acesso em: 28 ago. 2012.

WATSON, J. D. et al. DNA Recombinante Genes e Genomas. $3^{\text {a }}$ Edição. Porto Alegre: Artmed Editora S.A., 2009.

WILSON, E. O. A Conquista Social da Terra. São Paulo: Companhia das Letras, 2013.

ZATZ, M. In: http://veja.abril.com.br/blog/genetica/tag/sexo-do-bebe/. Acesso em: ago. 2012.

ZATZ, M. Projeto Genoma Humano e Ética. São Paulo em perspectiva, São Paulo, v.14, n. 3, julho/ set. 2000. Disponível em: <www.scielo.br/scielo.php?script=sci_arttext\&pid=S0102-*88392000000300009>. Acesso em: 28 ago. 2012. 